\title{
Perovskite Single-Crystal Solar Cells: Going Forward
}

\section{Bekir Turedi, ${ }^{1}$ Vishal Yeddu, ${ }^{2,3}$ Xiaopeng Zheng, ${ }^{1}$ Do}

\section{Young Kim, ${ }^{3}$ Osman M. Bakr, ${ }^{1 *}$ and Makhsud I.}

\section{Saidaminov $^{2 *}$}

${ }^{1}$ Division of Physical Sciences and Engineering, King Abdullah University of Science and Technology (KAUST), Thuwal 23955-6900, Kingdom of Saudi Arabia

${ }^{2}$ Departments of Chemistry and Electrical \& Computer Engineering, Centre for Advanced Materials and Related Technologies (CAMTEC), University of Victoria, Victoria V8P 5C2, BC, Canada

${ }^{3}$ School of Materials Science and Engineering, Oklahoma State University, Tulsa, Oklahoma 74106, United States

AUTHOR INFORMATION

\section{Corresponding Author}

*Email: osman.bakr@kaust.edu.sa and msaidaminov@uvic.ca 
ABSTRACT - Most efficient perovskite solar cells are based on polycrystalline thin films; however, substantial structural disorder and defective grain boundaries place a limit on their performance. Perovskite single crystals are free of grain boundaries, leading to significantly low defect densities and thus hold promise for high-efficiency photovoltaics. However, the surfaces of perovskite single crystals present a major performance bottleneck because they possess a higher density of traps than the bulk. Hence, it is crucial to understand and control the surface trap population to fully exploit perovskite single crystals. This perspective highlights the importance of surface-trap management in unleashing the potential of perovskite single-crystal photovoltaics and discusses strategies to take this technology beyond the proof-of-concept stage.

\section{TOC GRAPHICS}

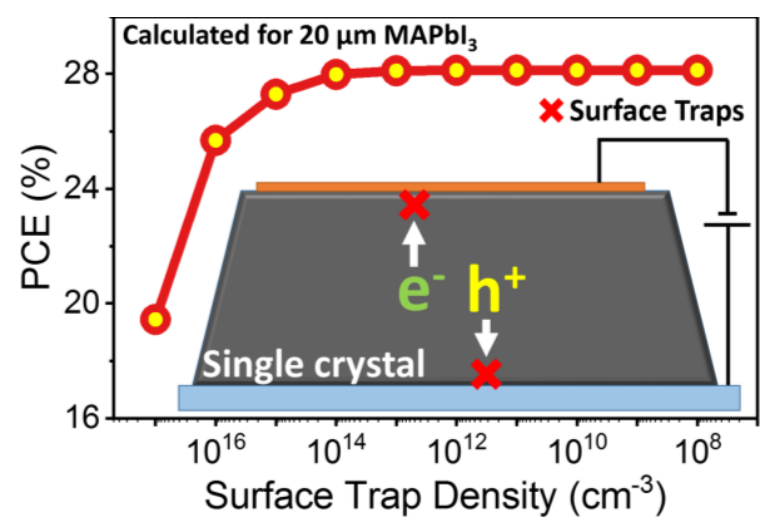




\section{MAIN TEXT}

Can perovskite single-crystal photovoltaics outperform their polycrystalline counterparts? For conventional semiconductors (such as $\mathrm{Si}, \mathrm{Ge}$, and $\mathrm{GaAs}$ ), the answer is very straightforward: single-crystal semiconductors perform better than polycrystalline thin films in photovoltaics, as crystals have significantly lower defect densities. ${ }^{1}$ However, the situation (so far) is different for perovskites: the best performances to date have been achieved with polycrystalline thin films. Interest in single-crystal perovskite solar cells (SC-PSCs) lags far behind that in polycrystalline perovskite solar cells (Pc-PSCs). Pc-PSCs have received most of the attention partly due to the relative ease of their fabrication; they have also enjoyed a rapid increase in performance over the past seven years. However, the efficiency of Pc-PSCs, as expected, has now plateaued due to their inherently high density of structural defects [grain boundaries (GBs), point defects, etc. ${ }^{2} .^{2-7}$

Compared with polycrystalline perovskites, perovskite single crystals have trap densities that are several orders of magnitude lower, leading to a 100 times longer carrier diffusion length. While single crystals can perform beyond the limits of Pc-PSCs, ${ }^{8-9}$ their synthesis and device integration are complex; for that reason, scarce attention was paid to SC-PSCs. Indeed, there are

only a handful of reports on SC-PSCs, with most of them indicating sub-13\% efficiency. ${ }^{10}$ Table S1 summarizes device configuration and performance of SC-PSCs reported up to date. The first SC-PSC breaking this barrier was reported in 2017, fabricated using methylammonium lead iodide $\left(\mathrm{MAPbI}_{3}\right)$ single crystals and exhibiting a $17.8 \%$ efficiency. ${ }^{11}$ The second quantum leap in SCPSCs efficiency occurred in 2019, reached $21 \%$ through the controlled growth of perovskite single-crystal thin films. ${ }^{12}$ Since then, the highest efficiency reported for SC-PSCs was $21.93 \%$, achieved through surface modifications. ${ }^{13}$ This value is not far behind the efficiency of state-of- 
the-art Pc-PSCs. However, it is still distant from the theoretical Shockley-Queisser (S-Q) limit of $31.64 \%$ for a $1.5-\mathrm{eV}$ bandgap semiconductor. ${ }^{14-15}$

One question that naturally arises is this: If perovskite single crystals are superior to polycrystalline films, what is limiting them in the context of solar cells? Although the bulk trap density is exceptionally low, the surface trap density is significantly high on perovskite single crystals, ${ }^{16-18}$ leading to performance loss. ${ }^{2,19-21}$ Another question is what is more viable for advancing PSC technology, lowering the bulk trap density in polycrystalline films or the surface trap density of single crystals? ${ }^{6,19}$ To address these questions, this perspective discusses how the surface chemistry and physics of perovskite single crystals affect their photovoltaic performance and proposes pathways to diminish their harmful effects, which are standing in the way of the application of these materials beyond the proof-of-concept phase.

Figure 1a summarizes the best efficiencies achieved for single-junction solar cells. ${ }^{22}$ Naturally, single crystals, because of their low concentration of structural defects, produce the highest photovoltaic efficiencies, ${ }^{23}$ while corresponding polycrystalline solar cells generally offer lower efficiencies ${ }^{24-25}$ however, perovskites do not obey this norm —at least not at the moment.

Grain boundaries (GBs) are dominant energy loss centers in conventional polycrystalline solar cells. Substantial nonradiative recombination at grain boundaries leads to a low short-circuit current $\left(J_{\mathrm{SC}}\right)$, open-circuit voltage $\left(V_{\mathrm{OC}}\right)$, and-occasionally-fill factor $(\mathrm{FF})$ in solar cells. ${ }^{26}$ These grain boundaries can be effectively passivated (e.g., in Si, CdTe, and CIGS polycrystalline solar cells). ${ }^{23-24}$ Another way to avoid the side effects of GBs is using grain-free, single-crystal materials, as is the case for $\mathrm{GaAs}, \mathrm{Si}$, and $\mathrm{CdTe}$. However, single crystals are not available for most emerging 
thin-film solar materials (such as CIGS, inorganic CZTSSe, quantum-dot, dye-sensitized, and amorphous $\mathrm{Si}: \mathrm{H}$ solar cells).

Figure $1 \mathrm{~b}$ compares the performance of polycrystalline and single-crystal forms of several materials. Performance-limiting deep traps for polycrystalline GaAs cells are dislocations in $\mathrm{GBs} ;{ }^{24}$ due to the absence of effective GB passivation techniques, the efficiency of these cells is lower-by nearly 10 absolute power points - than that of GaAs thin film single-crystal solar cells. ${ }^{24,27}$ It is calculated that GaAs polycrystalline cells require grain sizes on the order of tens of microns to achieve efficiencies of over $20 \% .{ }^{24}$ GaAs thin film single-crystals currently hold a record efficiency of $29.1 \%$ among all types of single-junction solar cells, a result achieved by effective surface/interface passivation and precise crystal growth to reduce the density of dislocations. ${ }^{22,27-28}$

Multicrystalline (polycrystalline) Si (mc-Si) suffers from intrinsic defects such as dangling bonds, dislocations, and extrinsic metal impurities concentrated at GBs. Consequently, the grain size should be large, at least $10 \mathrm{~mm}$, to achieve high efficiencies. ${ }^{29}$ Control over crystallization to reduce metal impurities in GBs and to produce large-grain wafers allowed this technology to reach $23.3 \%$ efficiency. ${ }^{22,27,29}$ In single-crystal Si (c-Si), passivation of surface Si dangling bonds with $\mathrm{H}$ atoms enabled the record c-Si efficiency of $26.7 \% .^{22,27,30}$

GBs in polycrystalline CdTe lead to the loss of device performance. $\mathrm{CdCl}_{2}$ heat treatment significantly passivates the GBs; also, segregation of $\mathrm{Cl}$ atoms to the edge of p-type CdTe grains converts the surface to n-type CdTe, creating a local p-n-p junction. ${ }^{31}$ This unconventional GBassisted charge collection in CdTe films has led to a PCE of 22.1\%, higher than the PCE of their single-crystal counterparts, $19.7 \% .^{22,27,32}$ 

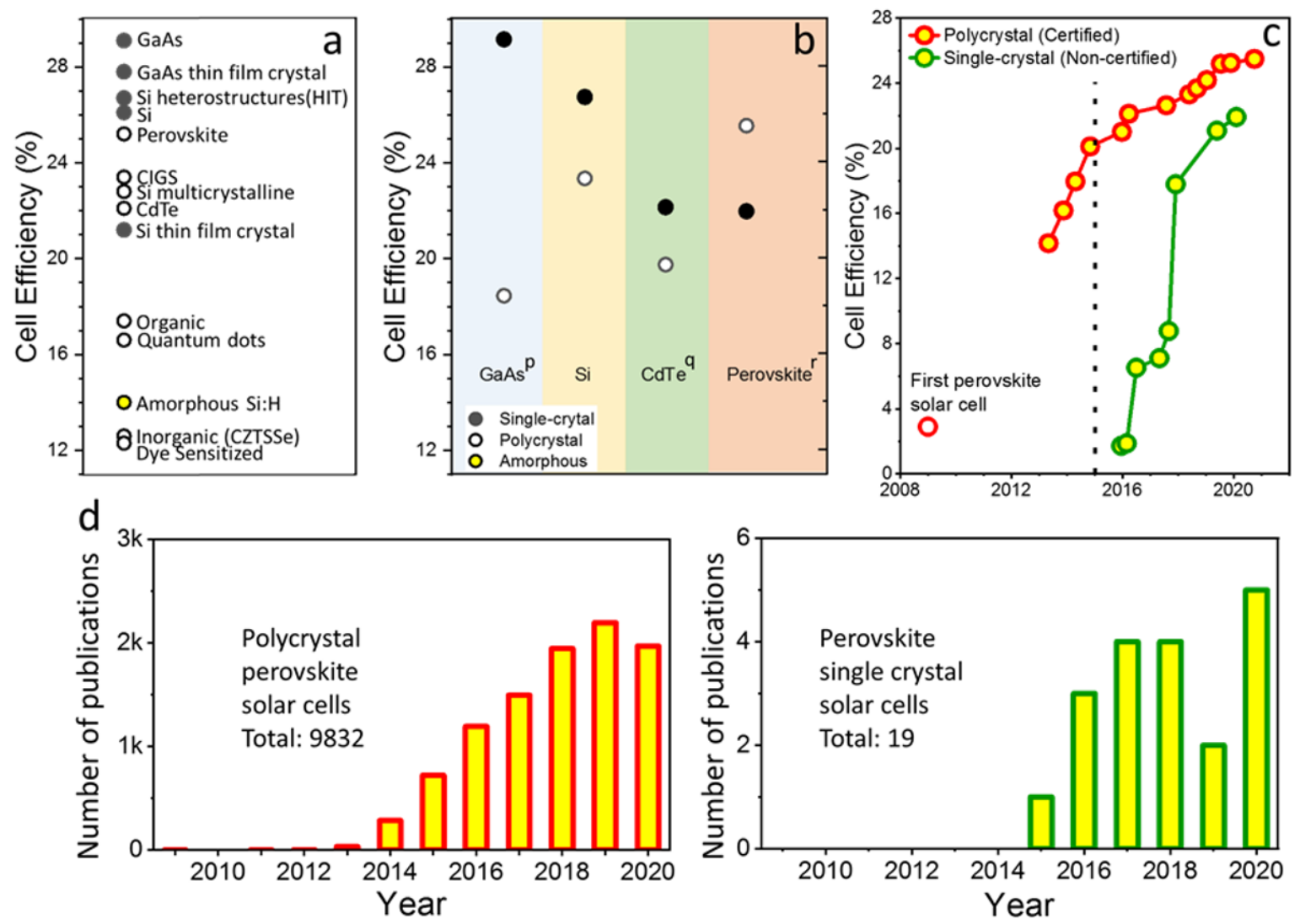

Figure 1: (a) Highest certified efficiencies for single-junction solar cells. (b) Best-efficiency comparison of polycrystalline and single-crystal solar cells of GaAs, $\mathrm{Si}, \mathrm{CdTe}$, and perovskite. The efficiency data for polycrystalline GaAs (certified), single-crystal CdTe (certified) and singlecrytals perovskite are taken from the reference denoted by letters $\mathrm{p}^{24}, \mathrm{q}^{32}, \mathrm{r}^{13}$, respectively. (c) Evolution of best perovskite solar cell efficiency for polycrystalline (certified) and single-crystal (non-certified) thin films over time. The dotted line marks the first reports of a single-crystal perovskite. Certified data were extracted from the NREL Best Research-Cell Efficiency Chart ${ }^{22}$ unless otherwise stated. (d) The year-wise publication history of perovskite solar cells based on data is obtained from Web of Science. (For polycrystalline solar cells, the results were obtained by searching for "perovskite solar cell," excluding results containing the words "single crystal" and "monocrystalline". For single-crystal solar cells, the results were searched for manually in the literature.)

The adverse effects of deep trap levels are indisputable, as summarized above for conventional photovoltaic semiconductors. Organic-inorganic hybrid perovskites have earned the distinction of being defect-tolerant materials, as the formation of deep levels in their bulk is thermodynamically unfavorable. ${ }^{33-34}$ Whether GBs in perovskite produce deep trap states remains 
a matter of active investigation, ${ }^{35-37}$ but it is clear that archetypical small-grain perovskites have abundant GBs. ${ }^{2}{ }^{26}$ Nevertheless, the PCE of Pc-PSCs has reached $25.5 \%$ in less than ten years (Figure $1 \mathrm{~b}$ and $\mathrm{c}$ ) and has now almost plateaued.

$\mathrm{MAPbI}_{3}$ single crystals prepared by antisolvent vapor crystallization (AVC) and topseeded solution-growth crystallization (TSSC) from an acidic solution, both reported in 2015, have exhibited a trap density of $\sim 10^{10} \mathrm{~cm}^{-3}$, lower than that of their polycrystalline counterparts by a factor of $10 .^{6,8-9}$ These methods require one week to produce millimeter-scale crystals. They hence have not been adapted to photovoltaic device applications. Lateral devices made using bulk materials and wafers sliced from bulk crystals have shown less than $2 \%$ efficiency. ${ }^{38-39}$ Inverse temperature crystallization (ITC) of high-quality perovskite single crystals, a process that can be completed within several hours, ${ }^{40}$ has become a popular crystallization technique for fabricating single-crystal optoelectronics, such as photodetectors, lasers, transistors, and photovoltaics. ${ }^{10,41-43}$ ITC-grown $\mathrm{MAPbI}_{3}$ single crystals have a low trap density of $1.4 \times 10^{10} \mathrm{~cm}^{-3}$, lower than that of a wide range of decade-old and emerging photovoltaics semiconductors, including GaAs ( $n_{\text {traps }} \sim$ $\left.10^{13}-10^{15} \mathrm{~cm}^{-3}\right)^{44}, \mathrm{mc}-\mathrm{Si}\left(n_{\text {traps }} \sim 10^{13}-10^{15} \mathrm{~cm}^{-3}\right)^{45-46}, \mathrm{CdTe} / \mathrm{CdS}\left(n_{\text {traps }} \sim 10^{11}-10^{13} \mathrm{~cm}^{-3}\right),{ }^{47}$ and CIGS $\left(n_{\text {traps }} \sim 10^{12}-10^{13} \mathrm{~cm}^{-3}\right)^{48}$. Only high-quality n-type c-Si, grown and re-annealed at thousands of degrees Celsius, offers comparable or better trap densities $\left(10^{8}<n_{\text {traps }}<10^{15} \mathrm{~cm}^{-3}\right)^{49}$.

Modified ITC for growing thin single crystals between two hydrophobic conductive substrates has enabled the fabrication of vertical SC-PSCs with efficiencies of up to $21.93 \%$ (Figure 1c). ${ }^{11,13,50}$ This value is lower than that of polycrystalline counterparts, despite these counterparts having a significantly high trap density. Figure 1d compares the number of publications on Pc-PSCs and SC-PSCs reported to date; whereas the number of Pc-PSC-related papers reaches $\sim 10,000$, there are only 19 SC-PSCs-related publications. This comparison shows 
that single-crystal perovskite photovoltaics are in their infancy and that the most intriguing findings are yet to come.

The meager interest in SC-PSCs is due to the absence of suitable methods for synthesizing sufficiently thin single-crystal perovskites, free-standing or firmly attached to a substrate, across large lateral dimensions. A few methods have been employed to control the thickness of perovskite single crystals, such as cavitation-triggered asymmetric crystallization, ${ }^{51}$ thin-wafer cutting from a bulk single crystal, ${ }^{39}$ free-standing wafer growth on the surface of a growth solution, ${ }^{52}$ perovskite single-crystal microarray growth on substrate, ${ }^{53-54}$ and space-limited ITC ${ }^{11,50}$.

Peng et al. reported the first vertical SC-PSC based on $\mathrm{MAPbBr}_{3}$ crystals grown by sonication-triggered AVC. ${ }^{51}$ This method was not suitable for $\mathrm{MAPbI}_{3}$ crystals but still demonstrated the potential of perovskite crystals to be used in vertical devices. Rao et al. utilized space-limited ITC to grow $16-\mu$ m-thick $\mathrm{MAPbBr}_{3}$ crystals with lateral dimensions of $6 \times 8 \mathrm{~mm}^{2}$ on a substrate and achieved $7.11 \%$ PCE. Such thin crystals exhibited a trap density of $2.5 \times 10^{10} \mathrm{~cm}^{-3}$, comparable to that of ITC-grown bulk crystals. ${ }^{55}$ Because $\mathrm{MAPbBr}_{3}$ is not a widely used solar material due to its relatively high bandgap and there is a lack of studies on mixed cation/anion SCPSCs, we will hitherto focus on $\mathrm{MAPbI}_{3}$-based SC-PSCs.

Chen and Dong et al. ${ }^{11}$ demonstrated vertical $\mathrm{MAPbI}_{3}$-based SC-PSCs fabricated using space-limited ITC (Figure 2a). An inverted solar cell configuration [ITO/poly(triarylamine) (PTAA)/MAPbI 3 single crystal/phenyl-C61-butyric acid methyl ester (PCBM)/C60/bathocuproine (BCP)/Copper $(\mathrm{Cu})$ ] yielded $17.8 \%$ efficiency with a $10-\mu$ m-thick crystal (Figure $2 \mathrm{~b})$. Surface passivation with methylammonium iodide (MAI) was necessary to heal the surface, which was deficient in MAI due to the high growth temperature used. ${ }^{11,56}$ We reported a $20-\mu \mathrm{m}$-thick $\mathrm{MAPbI}_{3}$ 
single crystal carefully grown and stored in an inert environment that surpassed the $20 \%$ PCE benchmark (PCE of $21.09 \%, J_{\mathrm{SC}}$ of $23.46 \mathrm{~mA} \mathrm{~cm}{ }^{-2}, V_{\mathrm{OC}}$ of $1.08 \mathrm{~V}$, and FF of $83.5 \%$ ) (Figure 2c). ${ }^{12}$ In a later study, we showed that low-temperature growth improved the $V_{\mathrm{OC}}$ from 1.08 to $1.144 \mathrm{~V}$ and the PCE to a value of $21.93 \%\left(J_{\mathrm{SC}}\right.$ of $23.68 \mathrm{~mA} \mathrm{~cm}^{-2}$ and FF of $81 \%$; see Figure $\left.2 \mathrm{~d}\right){ }^{13}$ $J-V$ hysteresis, which is largely related to vacancy-mediated migration of iodide ions, is a major issue in Pc-PSCs. ${ }^{57-59}$ The hysteresis is expected to be suppressed for a SC-PSC having the same absorber thickness as Pc-PSC due to a lower densities of defects. However, reported SC-PSCs are 20-30 times thicker than conventional Pc-PSCs. Therefore, a small hysteresis is still observed in SC-PSCs due high absolute amount of defects in thick single crystal (Figure $2 \mathrm{c}, \mathrm{d}$ ). To eliminate hysteresis, the thickness should be decreased in parallel to developing new methods to suppress ion migration.
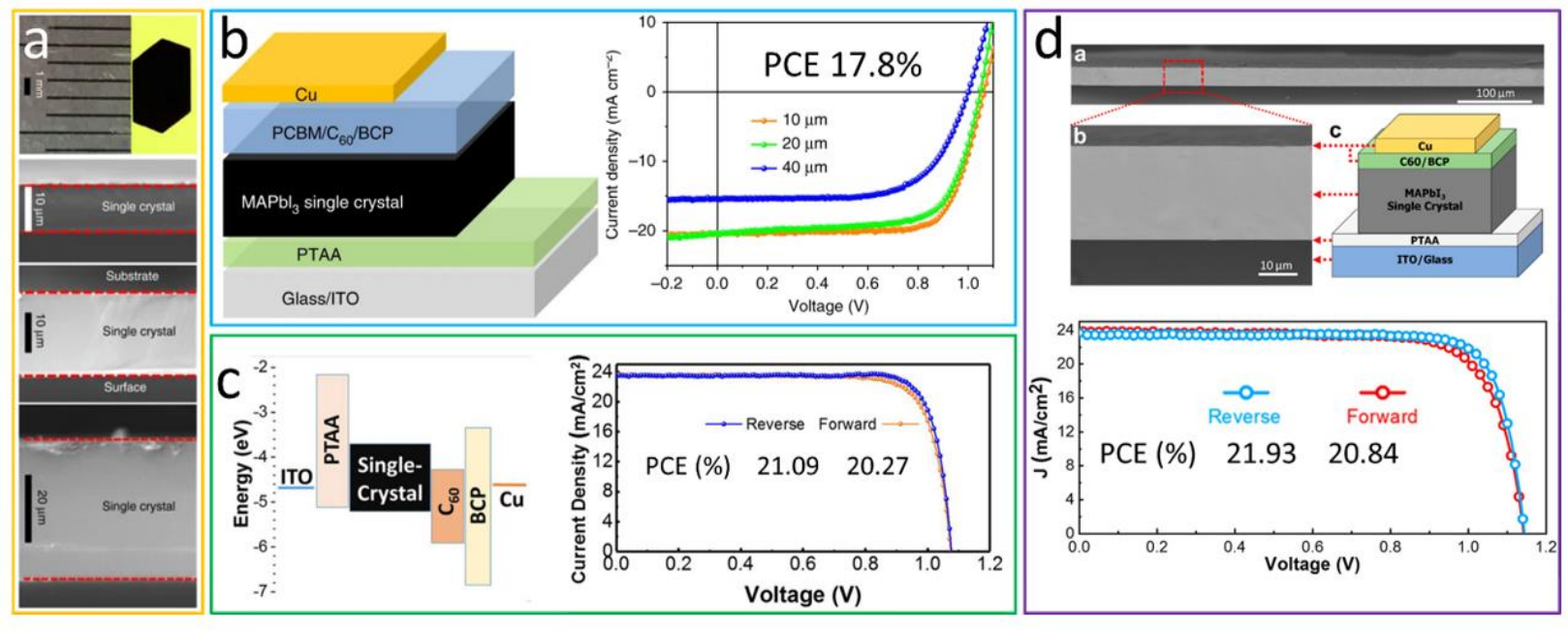

Figure 2: (a) Optical and SEM cross-sectional micrographs of thin $\mathrm{MAPbI}_{3}$ single crystals of various thicknesses. (b) Device architecture and $J-V$ curves for thin $\mathrm{MAPbI}_{3} \mathrm{SC}-\mathrm{PSC}$ of different thicknesses. Reprinted with permission. ${ }^{11}$ Copyright 2017, Nature Publishing Group. (c) Energy band diagram and $J-V$ curves obtained along different scanning directions of $\mathrm{MAPbI}_{3} \mathrm{SC}_{-\mathrm{PSC}}$ fabricated, stored, and measured in a $\mathrm{N}_{2}$ environment. Reprinted with permission. ${ }^{12}$ Copyright 2019, American Chemical Society. (d) Device configuration and SEM cross-sectional micrographs of surface-modified thin $\mathrm{MAPbI}_{3}$ single crystals formed by low-temperature growth and 
corresponding $J-V$ curves obtained along different scanning directions. Reprinted with permission. ${ }^{13}$ Copyright 2020, American Chemical Society.

The diffusion length of perovskite single crystals has been a subject of debate as various methods (SCLC, 1D, and 3D methods) have suggested values ranging from one micron to millimeters. The external quantum efficiency (EQE) of recent studies ${ }^{12-13}$ was consistently above $80 \%$, indicating a charge carrier diffusion length longer than $20 \mu \mathrm{m}$ in these materials, reconfirming the excellent charge transport properties of these ITC-grown single crystals. ${ }^{60}$

Although perovskite single crystals have exceptional charge transport properties, their surface dangling bonds, dislocations, and chemical contamination hinder their intrinsic properties. In contrast to the bulk diffusion coefficient (Figure $3 a),{ }^{8-9}$ the surface recombination velocity (SRV) of perovskite single crystals is higher than that of polycrystalline films by a factor of 6 (Figure 3a). The photoluminescence (PL) lifetime of the $\mathrm{MAPbI}_{3}$ crystal surface is comparable or inferior to that of the polycrystalline film surface. ${ }^{16,31}$

Light intensity-dependent impedance spectroscopy (IS) and transient photovoltage (TPV) measurements indicated that surface recombination in single crystals becomes a dominant factor at light intensities near 1-sun illumination (Figure 3b-c), which suggests that surface recombination limits the lifetime at a high light intensity. ${ }^{9}$ The local distortion of the crystal structure, which is enhanced by introducing more structural defects, results in the widening of the bandgap at the surface of perovskite single crystals (Figure 3d) ${ }^{61-62}$ Simultaneously, the fast decaying part of the PL recombination lifetime shows a dramatic contrast between the surface and bulk of the crystal (Figure 3e). PL recombination dynamics indicate that defect-induced nonradiative recombination is more dominant in the perovskite crystal surface than its bulk, as illustrated in Figure $3 \mathrm{f}$. The 
nonradiative recombination in the surface is dominantly governed by $\mathrm{Pb}^{0}$ and $\mathrm{PbI}_{2}$ defects located excessively on the surface, a detailed discussion will be given later in this article.
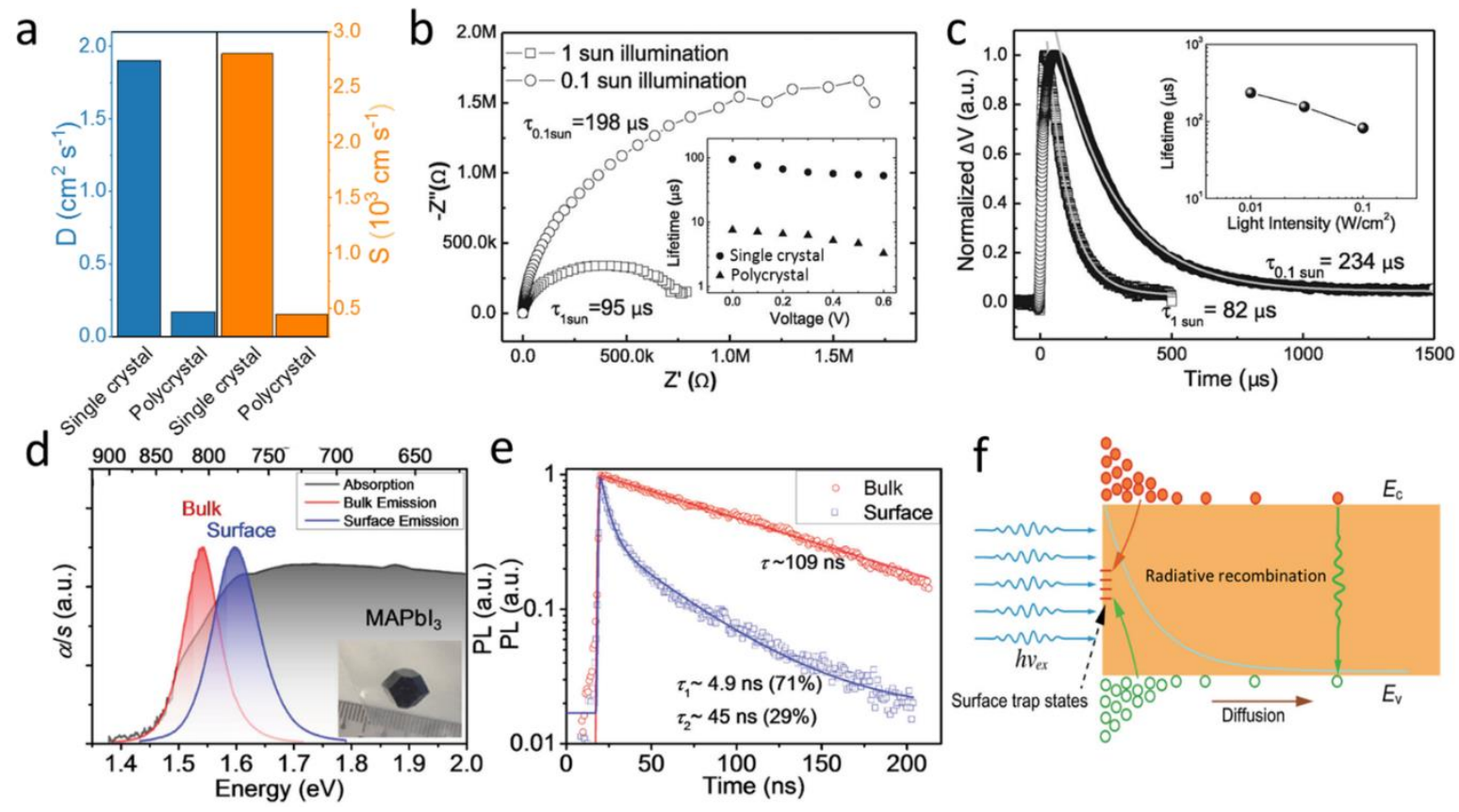

Figure 3: (a) Diffusion coefficient (D) and surface recombination velocity (S) of single-crystal and polycrystalline $\mathrm{MAPbI}_{3}$. Data were taken from ref. ${ }^{17}$ (b) Impedance spectra (IS) and (c) transient photovoltaic (TPV) decay curves of $\mathrm{MAPbI}_{3}$ single-crystal devices under 0.1 - and 1-sun illumination. The inset of (b) is the recombination lifetime calculated from IS measurements of the $\mathrm{MAPbI}_{3}$ single-crystal and the polycrystalline thin-film devices at various voltage biases under 1sun illumination. The inset of (c) is the charge recombination lifetime calculated from TPV measurements of a $\mathrm{MAPbI}_{3}$ single-crystal device under various light intensities. Reprinted with permission. ${ }^{9}$ Copyright 2015, AAAS. (d) $\mathrm{MAPbI}_{3} \quad \alpha / \mathrm{s} \quad$ (absorption/scattering), bulk emission $\left(\lambda_{\mathrm{ex}}=1200 \mathrm{~nm}\right)$, and surface emission $\left(\lambda_{\mathrm{ex}}=600 \mathrm{~nm}\right)$ profiles. (inset: $\mathrm{MAPbI}_{3}$ single-crystal image) and (e) $\mathrm{MAPbI}_{3}$ bulk emission and surface transient photoluminescence (TRPL) dynamics at the same wavelengths. Reprinted with permission. ${ }^{61}$ Copyright 2016, Wiley. (f) Schematic representation of PL recombination dynamics into bulk and surface recombination channels. Reprinted with permission. ${ }^{63}$ Copyright 2016, AAAS.

To understand how detrimental the bulk and surface defects of single crystals are to the photovoltaic efficiency, we conducted SCAPS simulations. ${ }^{64}$ A thin $\mathrm{MAPbI}_{3}$ single crystal was modeled in three parts: the bulk, the top surface (perovskite/ $\mathrm{C}_{60}$ interface), and the bottom surface (PTAA/perovskite interface) (Figure 4a, Figure S1a). We located the surface defects at a depth of 
$10 \mathrm{~nm}$ from the interfaces; ${ }^{65-66}$ in addition, we added a region that increases the defect density exponentially from the bulk to the surface level of defect density. ${ }^{18}$ The additional layer was added because optical measurements suggested that the depth of the surface defects is comparable to the depth of light penetration at the wavelength of surface TRPL measurements, i.e., $\sim 80 \mathrm{~nm}$ for 532 nm. ${ }^{16,67}$ The thickness-dependent performance simulation shows that the device performance is maximized at $2.5 \mu \mathrm{m}$ (Figure S2). We chose the absorber thickness of $20 \mu \mathrm{m}$ to make the simulation consistent with the reported highest efficiency SC-PSCs fabricated from $\sim 20 \mu \mathrm{m}$-thick perovskite single crystals. We simulated the $J-V$ curves for two situations: (i) a variation in bulk defect density with a constant surface defect density $\left(\right.$ at $10^{17} \mathrm{~cm}^{-3}$ ) on both sides (Figure $4 \mathrm{~b}, \mathrm{c}$ ) and (ii) a variation in surface defect density on both sides with a constant bulk defect density (at $10^{11}$ $\mathrm{cm}^{-3}$ ). The bulk and surface defect densities were chosen in agreement with previously reported data. $^{8-9,16,40,61,65-66,68}$

Varying the bulk defect density from $10^{12}$ to $10^{8} \mathrm{~cm}^{-3}$ (Figure S1b) leads to a slight increase in efficiency, while $V_{\mathrm{OC}}$ shows no significant change (Figure 4b). Trap-free 20- $\mu \mathrm{m}$-thick SC-PSCs show a substantial enhancement in performance. Varying the surface defect densities from $10^{17}$ to $10^{13}$ (Figure S1c) leads to an improvement in $J_{S C}\left(\right.$ till $10^{16}$ traps per $\mathrm{cm}^{-3}$ ) and $V_{\mathrm{OC}}$ (up to $10^{14} \mathrm{~cm}^{-}$ ${ }^{3}$, see Figure $\left.4 \mathrm{c}\right)$. We repeated the same calculations with $2.5-\mu \mathrm{m} \mathrm{MAPbI}{ }_{3}$ single crystal and observed a similar trend in performance (Figure S3). The trends in the $V_{\mathrm{OC}}$ and performance after reduced surface trap density of SC-PSC are in agreement with the trends of Pc-PSCs. 3, 5, 69-72

Figure $4 \mathrm{~d}$ summarizes the simulations. The calculations clearly indicate that improving the bulk defect density does not imply an apparent increase in device efficiency at high surface defect densities. However, a low density of surface defects helps PSCs reach the performance of defectfree single-crystal solar cells. Reducing the surface defect density is more beneficial than reducing 
the bulk defect density; therefore, strategies for improving SC-PSCs should focus on ameliorating the surface of perovskite single crystals.

(a)

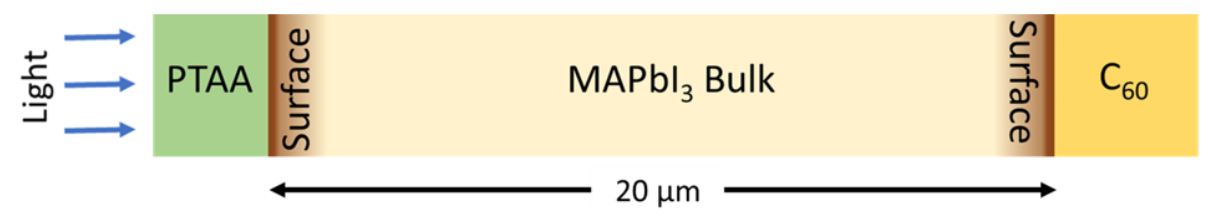

(b)

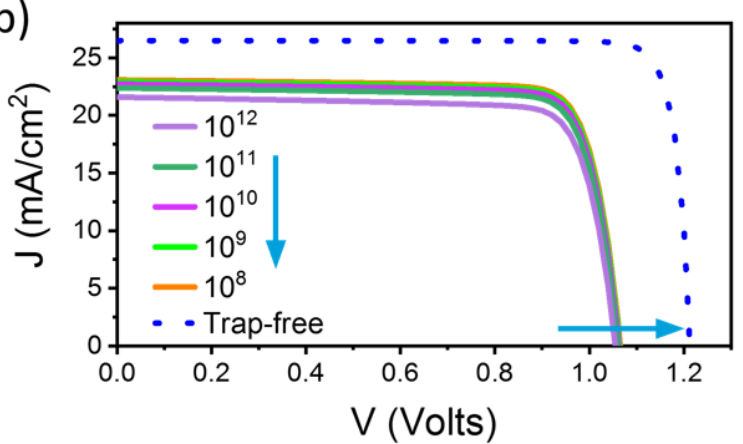

(c)
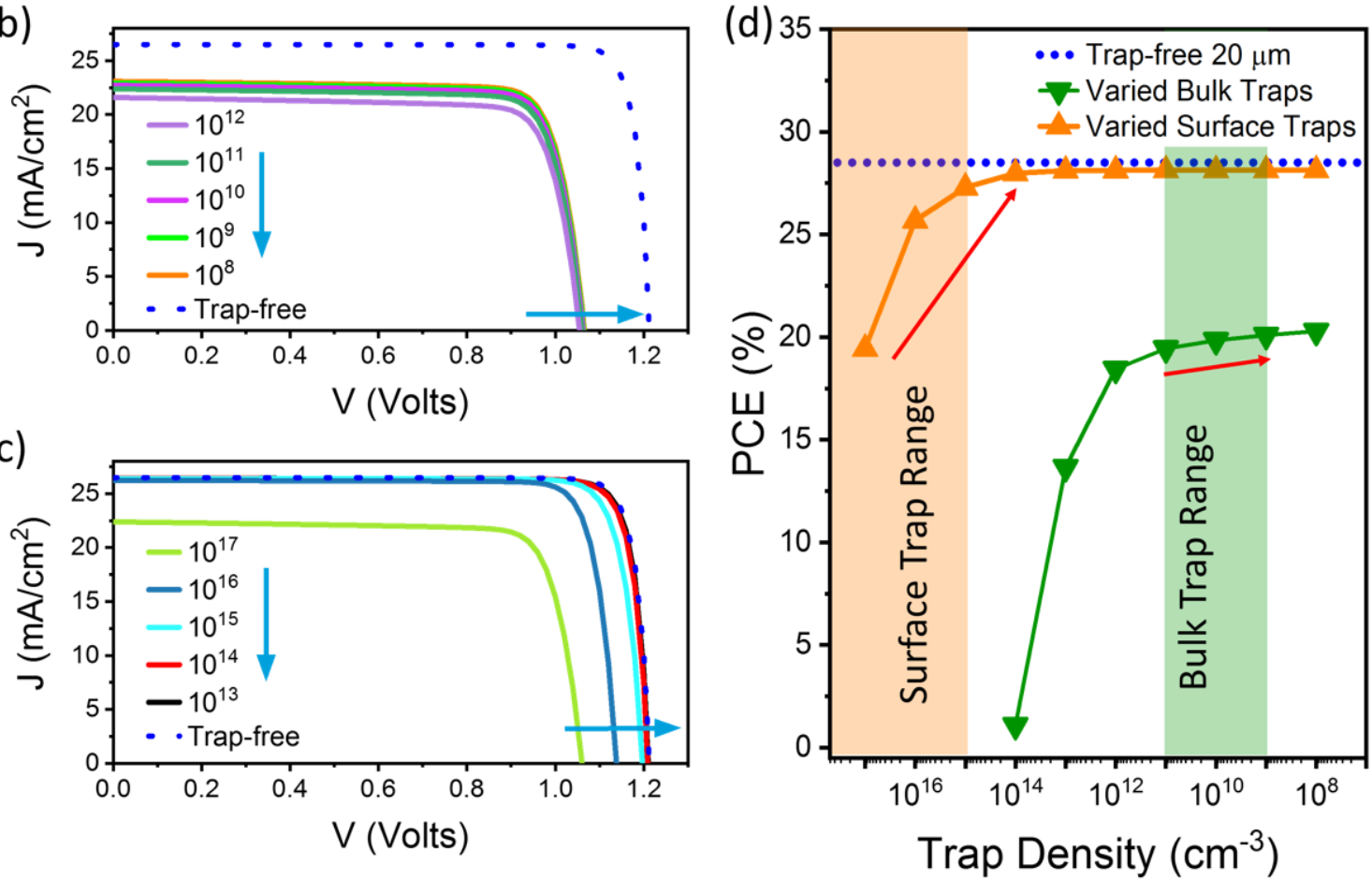

Figure 4: (a) The device architecture used to simulate thin SC-PSCs. The simulation details for the trap profiles is given in supplementary Figure S1. (b) The $J-V$ curves were obtained by simulation for a varying bulk trap density with the surface trap densities of perovskite/ $\mathrm{C}_{60}$ and perovskite/PTAA held constant at $10^{17} \mathrm{~cm}^{-3}$.(c) The $J-V$ curves were obtained by simulation for a varying surface trap density at perovskite/ $\mathrm{C}_{60}$ and perovskite/PTAA surfaces while bulk trap density was held constant at $1 \times 10^{11} \mathrm{~cm}^{-3}$. The dashed curve in (c) and (e) is the calculated $J-V$ curve for an ideal $20-\mu \mathrm{m} \mathrm{MAPbI}_{3}$ single crystal without surface or bulk traps. (d) Overall summary of the effect of bulk and surface trap densities on device efficiency with the trap densities of the remaining parts in the simulation held constant, as mentioned above. The orange region is the reported range for $\mathrm{MAPbI}_{3}$ surface defect densities, and the green region is the reported range for $\mathrm{MAPbI}_{3}$ single-crystal defect densities.

Although the bulk of a single crystal is nearly trap-free, a defect-rich crystal surface is a major bottleneck for further augmenting the PCE of SC-PSCs. ${ }^{13,18,71}$ The chemistry of surface 
defects depends on the synthesis conditions applied (I-rich, $\mathrm{Pb}$ - rich, or moderate) ${ }^{73-75}$ The escape of volatile products (e.g., decomposition of organics under thermal stress) leaves behind electronically harmful nonvolatile $\mathrm{PbI}_{2}$ and metallic $\mathrm{Pb}^{0}$ (Figure 5a,b). ${ }^{56,76-78}$

Managing the single-crystal growth process to avoid surface defect formation is one strategy to suppress trap states in SC-PSCs. A high temperature of $>120{ }^{\circ} \mathrm{C}$ in conventional perovskite thin single-crystal growth leads to a large number of surface trap states due to the escape of MAI (Figure 5b-e). ${ }^{13} \mathrm{~A}$ solvent-engineering approach using a mixture of propylene carbonate (PC) and $\gamma$-butyrolactone (GBL) allowed for the low-temperature $\left(<90{ }^{\circ} \mathrm{C}\right)$ ITC of $\mathrm{MAPbI}_{3}$ thin single crystals; as a result, the surface of the crystals was improved (Figure 5c,d), and the corresponding solar cells showed a $V_{\mathrm{OC}}$ of $1.15 \mathrm{~V}$ and an efficiency of $21.9 \%$ (Figure $5 \mathrm{e}$ ). ${ }^{13}$

Additive-assisted single-crystal growth also allows for the tunning of crystal shape and defect density. Feng et al. used a choline bromide additive to produce cuboid $\mathrm{CsPbBr}_{3}$ crystals with a low defect density. ${ }^{79}$ Jiao et al. reported a ligand-mediated strategy to control the shape ${ }^{80}$ We recently demonstrated that surface-anchoring alkylamine ligands suppress defect density, remarkably increasing $V_{\mathrm{OC}}$ and PCE. ${ }^{3}$ The facet-dependent optoelectronic properties derive from anisotropic defect species and densities. ${ }^{81}$ These large functional molecules are not incorporated into the perovskite lattice; they instead tune crystallization and surface defects with the aid of functional groups. ${ }^{75,82}$ 

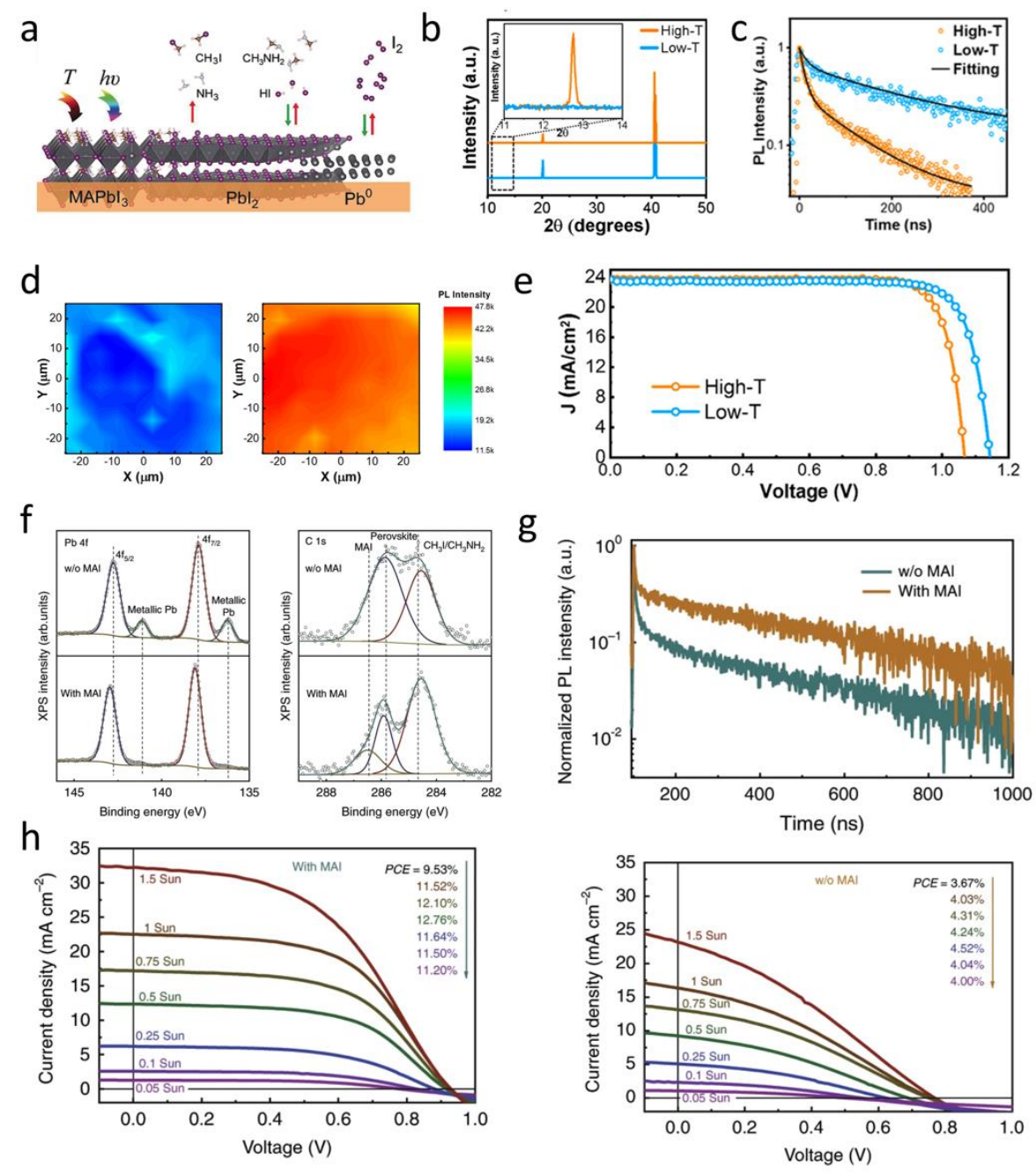

Figure 5: (a) $\mathrm{MAPbI}_{3}$ photodecomposition and thermal degradation processes leading to irreversible and reversible decomposition to organic volatile gas species leaving nonvolatile $\mathrm{PbI}_{2}$ and metallic $\mathrm{Pb}^{0}$ under illumination or mild heat conditions $\left(\sim 70^{\circ} \mathrm{C}\right)$. Reprinted with permission. ${ }^{56}$ Copyright 2020, Royal Society of Chemistry. (b) XRD $2 \theta$ patterns, (c) TRPL and (d) PL mapping comparisons of $\mathrm{MAPbI}_{3}$ single-crystal films grown at high temperature (High-T, $\sim 130{ }^{\circ} \mathrm{C}$ ) and low temperature (Low-T, $\sim 90{ }^{\circ} \mathrm{C}$ ) and (e) the corresponding $J-V$ curves of the champion devices. The inset of (b) shows a magnified peak for $\mathrm{PbI}_{2}$. Reprinted with permission. ${ }^{13}$ Copyright 2020, American Chemical Society. (f) XPS and (g) TRPL and measurements of $\mathrm{MAPbI}_{3}$ single-crystal surface before and after MAI treatment. (h) $J-V$ curves under different illumination of lateral $\mathrm{MAPbI}_{3}$ single-crystal solar cells. With and without MAI treatment. Reprinted with permission. ${ }^{76}$ Copyright 2020, Nature Publishing Group.

Another strategy to reduce the surface trap states is the post-treatment of as-grown single crystals. MAI post-treatment reduces the surface trap density of perovskite thin single crystals 2- 
to 5-fold. ${ }^{11}$ Song et al. demonstrated that MAI surface treatment could suppress the formation of metallic $\mathrm{Pb}^{0}$, one of the main types of surface traps in perovskite materials (Figure $5 \mathrm{f}, \mathrm{g}$ ), leading to a PCE increase from $4.0 \%$ to $11.5 \%$ in a lateral solar cell under 1 -sun illumination (Figure $5 \mathrm{~h}$ ). ${ }^{76}$

Lei et al. demonstrated that surface restructuring with a supersaturated $\mathrm{MAPbI}_{3} / \mathrm{GBL}$ solution is an effective method to restore and clean damaged or rough surfaces with decomposition residues (Figure $6 \mathrm{a}, \mathrm{b}){ }^{83}$ Mechanical polishing to remove as-grown defect-rich surfaces and expose a deeper perovskite lattice as a new surface can also reduce the surface trap density (Figure 6e). ${ }^{17}$ Further chemical surface treatment by converting the perovskite surface into a wide-bandgap oxysalt layer reduces the trap state density further by passivating undercoordinated surface lead centers (Figure 6f). ${ }^{18,84}$

Hydrophobic substrates facilitate the diffusion of ions and enable the continuous growth of thin perovskite single crystals up to several millimeters using a space-confinement method. ${ }^{11}$ Therefore, the options for transport layers on which the single crystals grow are limited, and devices are mostly based on a p-i-n device configuration. The highest efficiency Pc-PSCs are made from the $n-i-p$ structure. The best certified efficiencies of the $n-i-p$ and $p-i-n$ devices are $25.5 \%$ and $22.75 \%$, respectively. ${ }^{22,85}$ More efforts are needed to grow perovskite single crystals on different substrates to realize both n-i-p and p-i-n devices and develop strategies to address surface nonradiative recombination. The n-i-p device structure for SC-PSCs should be investigated more, since this architecture is expected to yield a better performance according to the trends observed in Pc-PSCs. Additionally, the defect passivation strategies, such as adding layers of PFN (HTL side) and LiF (ETL side), demonstrated in Pc-PSC studies can also be adapted to single-crystal devices to suppress surface nonradiative recombination (Figure $6 \mathrm{~g}, \mathrm{~h}){ }^{6}$ 
a
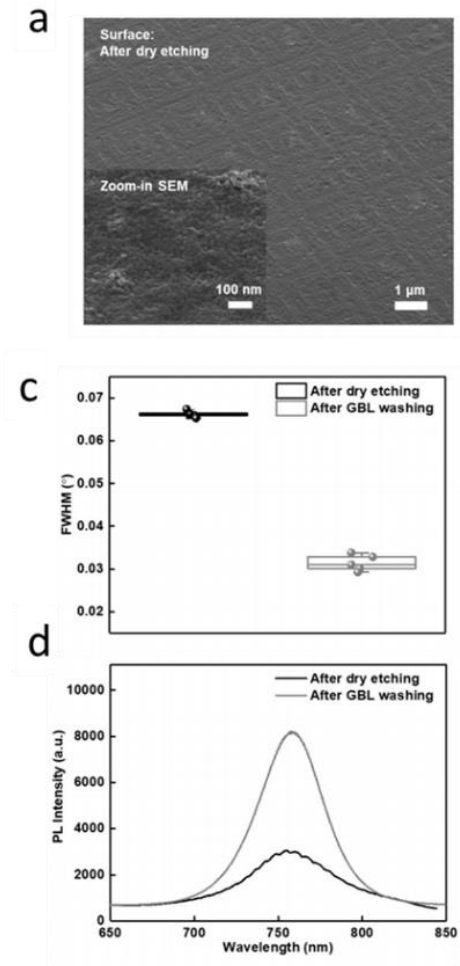
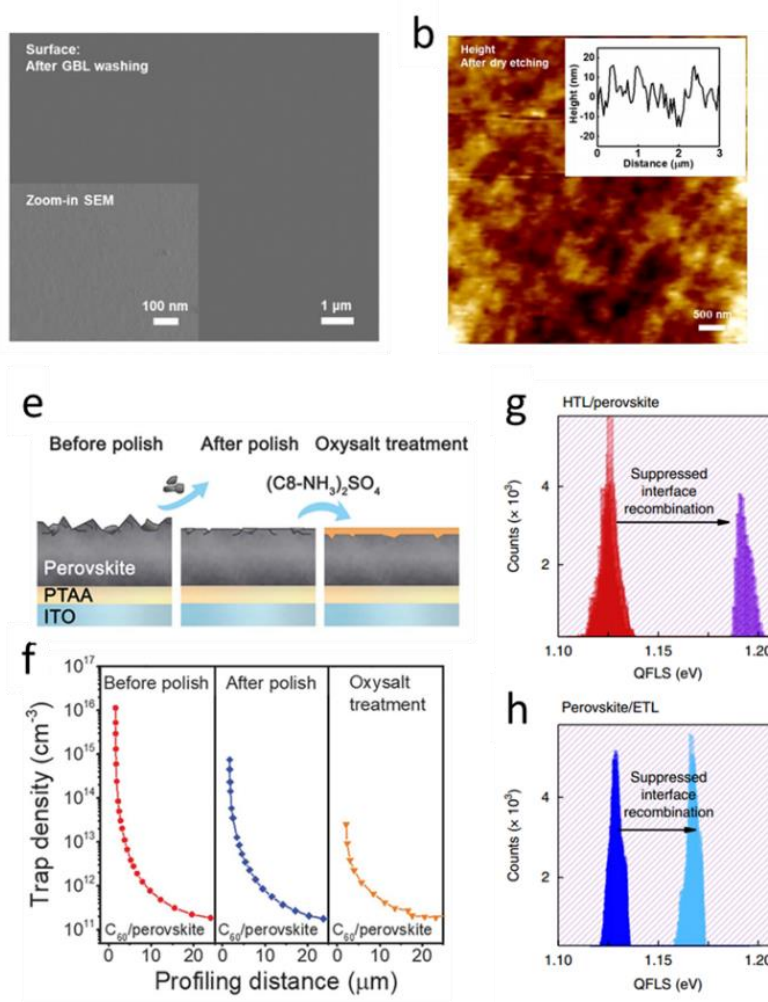
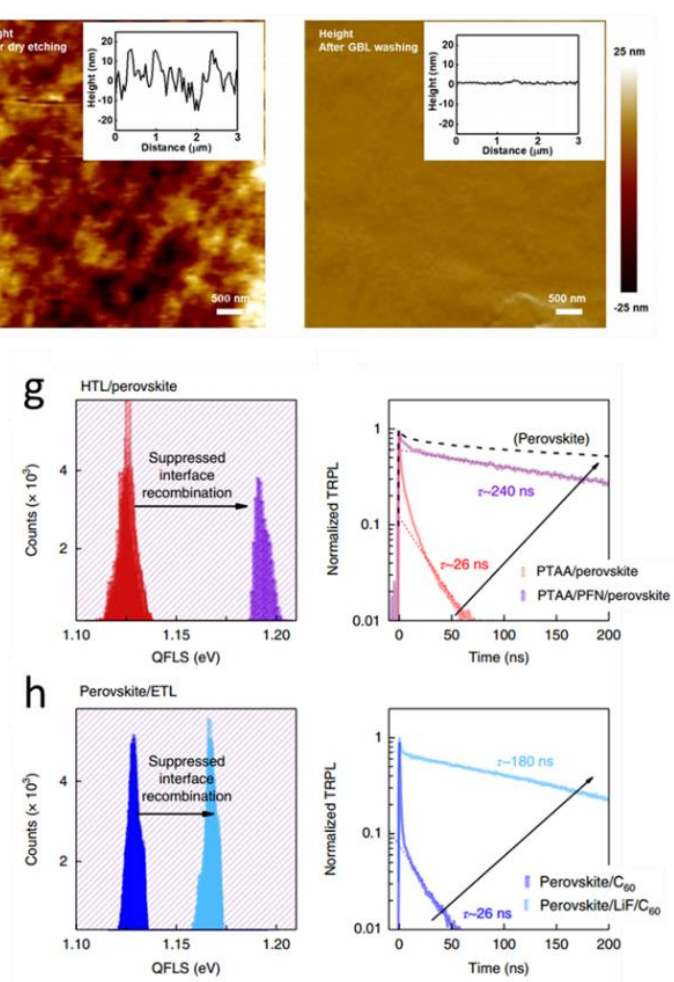

Figure 6: (a) Top-view SEM and (b) AFM images of a UV-ozone-damaged $\mathrm{MAPbI}_{3}$ single crystal and the crystal after GBL washing. (c) XRD $\omega$ scan measurements and (d) PL comparison showing differences before and after GBL washing. Reprinted with permission. ${ }^{83}$ Copyright 2020 , Nature Publishing Group. (e) Illustration of a $\mathrm{MAPbI}_{3}$ thin single crystal on a substrate before mechanical polishing, after mechanical polishing, and after oxysalt treatment. (f) Trap density near the $\mathrm{C}_{60} / \mathrm{MAPbI}_{3}$ single-crystal interface before mechanical polishing, after mechanical polishing, and after oxysalt treatment. Reprinted with permission. ${ }^{18}$ Copyright 2020, AAAS. Quasi-Fermi-level splitting (QFLS) histogram and TRPL measurements (g) of a PTAA/PFN/ polycrystalline $\mathrm{MAPbI}_{3}$ film on glass compared to a PTAA/polycrystalline $\mathrm{MAPbI}_{3}$ film $(\mathrm{h})$ and of a perovskite/LiF/ $\mathrm{C}_{60}$ film on glass compared to a $\mathrm{C}_{60}$ /polycrystalline $\mathrm{MAPbI}_{3}$ film. Reprinted with permission. ${ }^{6}$ Copyright 2020, Nature Publishing Group.

Perovskite single crystals offer a platform to investigate their fundamental properties as they have the smallest density of defects and degree of disorder possible due to the lack of GBs. The single crystals also promise high performance devices. As any technology in its early stage of development, solar cells based on perovskite single crystals faced a number of challenges to be solved in future. 
All efficient SC-PSCs are made of $\mathrm{MAPbI}_{3}$, an intrinsically unstable perovskite due to volatilization of methylamine. Although $\mathrm{MAPbI}_{3}$-based SC-PSCs are stable for 30 days at dark and at low humidity, ${ }^{11}$ their stability at maximum power point (MPP) conditions remains to be studied. Formamidinium lead iodide $\left(\mathrm{FAPbI}_{3}\right)$-based $\mathrm{Pc}$-PSCs have received significant attention after successful perovskite-polymorph stabilization. $\mathrm{FAPbI}_{3}$ offers improved stability and an optimal bandgap for solar cells. However, the growth of single crystals involves different crystallization dynamics, and hence methods known for stabilization of $\mathrm{FAPbI}_{3}$ thin films may not be directly applied for their single crystals. Phase stabilization and utilization of the FA-based single crystals is another pathway to increase the device stability and efficiency of SC-PSCs.

Another issue is that $\mathrm{MAPbI}_{3}$ undergoes a crystal structure phase transition from tetragonal to cubic phase at $\sim 60{ }^{\circ} \mathrm{C} .{ }^{86}$ Solar cells reach this temperature under MPP operation. As a result, $\mathrm{MAPbI}_{3}$ single-crystal-based devices experience loss of efficiency over long period of testing due to delamination induced by polymorphism-assisted volumetric change ${ }^{87}$. Therefore, compositional engineering is required to improve the stability of SC-PSCs. Mixed cation, e.g., based on FA and/or Cesium (Cs), perovskites ${ }^{88-90}$ with improved chemical and structural stability under MPP conditions offer a path towards stable SC-PSCs. Reducing the volatile MA content in single crystals will also lead to better surfaces, device performance and interfacial stability.

Free-standing thin perovskite single crystals could address delamination issues, since they will not require substrates to be grown on, and charge selective layers can be directly deposited on both sides of the crystals. However, currently-optimized $20 \mu \mathrm{m}$-thick perovskite single are brittle and challenging to handle. Thicker crystals could be more mechanically stable, but they do not have sufficient carrier transport. ${ }^{50,91}$ the diffusion length of perovskites should be increased to achieve by reducing bulk defect densities, compositional engineering and optimizing synthetic 
approaches. For commercialization, the device yield is critical. Due to the detachment of crystals, the device yield of SC-PSCs is currently poor with existing methods of growing on substrates. With the increase of crystal area, the yield drops further. Strategies for the growth of free-standing vertical SC-PSCs can increase the device yield for large area cells.

Lateral solar cells could also address delamination issues. Lateral SC-PCS based on $\mathrm{MAPbI}_{3}$ single crystals indeed showed a stable MPP operation for over $200 \mathrm{~h} .{ }^{76}$ However, lateral SC-PSCs suffer from low efficiencies and can be improved by suppressing surface traps.

Upscaling SC-PSCs is another major challenge. The best performing GaAs and Si single crystals are fabricated by chemical vapor deposition (CVD) on Ge crystals and wafer-slicing of a bulk ingot grown by Czochralski method at $1500{ }^{\circ} \mathrm{C}$, respectively. CVD requires lattice matching of substrate and epilayer, and was attempted on insulating substrates (e.g. $\mathrm{SrTiO}_{3}$ ) to form $\mathrm{CsPbBr}_{3}$ non-continuous thin films; ${ }^{92-93}$ this perovskite has a wide bandgap and is not suitable for photovoltaics.

Space limited ITC was developed to form free-standing perovskite wafers. ${ }^{50}$ In addition, wafer-slicing of ITC-grown large crystals also allows making thin perovskite wafers of over 100 $\mathrm{cm}^{2}$ lateral dimentions. ${ }^{91}$ However, both these methods offer crystal thicknesses of over $100 \mu \mathrm{m}$, 5x higher than perovskite diffusion length leading to low performing devices.

A-micron thick $\mathrm{MAPbI}_{3}$ single crystal sheets of over $25 \mathrm{~cm}^{2}$ dimensions can be epitaxially grown on patterned polymer sheets covering a bulk single-crystal. ${ }^{83}$ However, their efficiency peaked at $17 \%$ for $\mathrm{MAPbI}_{3}$ for $0.09 \mathrm{~cm}^{2}$ active area - significantly lower than the best SC-PSCs and dropped after thicknesses of $2 \mu \mathrm{m}$, indicating short carrier diffusion lengths. The $9 \mathrm{~cm}^{2}$ devices 
$\mathrm{Pb}-\mathrm{Sn}$ mixed devices made with this method achieved $10.3 \%$. This promising method can be further improved to achieve large-area efficient SC-PSCs.

In conclusion, we have shown that the efficiency of SC-PSCs is suppressed by their surface properties, and we have highlighted feasible methods for healing their surfaces. The most recent findings on curing the surface defects of perovskite single crystals during the growth process or enhancing the surface properties by post-treatment methods indicate the potential of these materials in further enhancing solar cell performance. To this end, new crystal growth and posttreatment methods exclusive to single crystals should be elaborated. The interlayers utilized to suppress nonradiative recombination should also be considered in parallel. Another key challenge is upscaling single-crystal growth to meet industrial standards. More efforts to improve the surface properties of perovskite crystals, combined with their already superior optoelectronic properties, can help SC-PSCs surpass their polycrystalline counterparts. While surpassing conventional polycrystalline PSCs is not the end goal for SC-PSCs, it is the authors' perspective that any material that relies on charge carrier diffusion, will eventually equilibrate in its highest quality.

\section{ASSOCIATED CONTENT}

The Supporting Information is available free of charge. Includes the details of the theoretical calculations.

\section{AUTHOR INFORMATION}

Corresponding Authors

Osman M. Bakr - Division of Physical Sciences and Engineering, King Abdullah University of Science and Technology, Thuwal 23955- 6900, Kingdom of Saudi Arabia; orcid.org/0000-00023428-1002; Email: osman.bakr@kaust.edu.sa

Makhsud I. Saidaminov $-{ }^{2}$ Departments of Chemistry and Electrical \& Computer Engineering, Centre for Advanced Materials and Related Technologies (CAMTEC), University of Victoria, Victoria V8P 5C2, BC, Canada; Email: msaidaminov@ uvic.ca 


\section{Notes}

The authors declare no competing financial interest.

\section{BIOGRAPHIES}

Bekir Turedi holds a B. Sc. in Physics (2013) and M.Sc. in Materials Science and Nanotechnology (2015) at Bilkent University, Turkey. He is currently a Ph.D. student in Prof. Osman Bakr group in Materials Science and Engineering at King Abdullah University of Science and Technology (KAUST). His research focuses on hybrid organic-inorganic materials, particularly, their use in optoelectronics.

Vishal Yeddu is a Ph.D. student in Chemistry under the supervision of Prof. Makhsud I. Saidaminov at the University of Victoria, Canada. His research focusses on developing highefficiency single crystal perovskite solar cells by interface and compositional engineering of metal halide perovskites.

Xiaopeng Zheng received his Ph.D. in Materials Science and Engineering from King Abdullah University of Science and Technology (KAUST) in 2020. He is currently a postdoctoral fellow in Prof. Osman Bakr group at KAUST. His research focuses on materials chemistry and optoelectronic devices of perovskite semiconducting materials.

Do Young Kim is an Assistant Professor in the School of Materials Science and Engineering at the Oklahoma State University. He received his Ph.D. in Materials Science and Engineering from the University of Florida in 2009. His research interests are in colloidal inorganic nanomaterials, metal halide perovskites and organic semiconductors based optoelectronic devices.

Osman M. Bakr holds a B.Sc. in Materials Science and Engineering from MIT (2003) and an M.S. and Ph.D. in Applied Physics from Harvard University (2009). He is currently Professor of Materials Science and Engineering at KAUST, Saudi Arabia. His research group focuses on the study of hybrid organic-inorganic materials; particularly, advancing their synthesis and selfassembly for applications in optoelectronics and catalysis.

Makhsud Saidaminov is a Canada Research Chair in Advanced Functional Materials, and an Assistant Professor at the University of Victoria, Canada. He received his Ph.D. from Moscow State University (2013). His research group specializes in the chemistry and physics of functional materials for applications in solar cells and optoelectronics. Website: https://saidaminovlab.com

\section{ACKNOWLEDGMENT}

The authors acknowledge funding support from King Abdullah University of Science and Technology (KAUST) and the Natural Sciences and Engineering Research Council (NSERC) of Canada. 


\section{QUOTES}

- Perovskite single crystals are free of grain boundaries, leading to significantly low defect densities and thus hold promise for high-efficiency photovoltaics.

- Naturally, single crystals, because of their low concentration of structural defects, produce the highest photovoltaic efficiencies, while corresponding polycrystalline solar cells generally offer lower efficiencies; however, perovskites do not obey this norm-at least not at the moment

- The surface recombination velocity (SRV) of perovskite single crystals is higher than that of polycrystalline films by a factor of 6 .

- Reducing the surface defect density is more beneficial than reducing the bulk defect density; therefore, strategies for improving SC-PSCs should focus on ameliorating the surface of perovskite single crystals.

\section{REFERENCES}

1. Luque, A.; Hegedus, S., Handbook of photovoltaic science and engineering. John Wiley \& Sons: 2011.

2. Luo, D.; Su, R.; Zhang, W.; Gong, Q.; Zhu, R., Minimizing non-radiative recombination losses in perovskite solar cells. Nature Reviews Materials 2020, 5 (1), 44-60.

3. Zheng, X.; Hou, Y.; Bao, C.; Yin, J.; Yuan, F.; Huang, Z.; Song, K.; Liu, J.; Troughton, J.; Gasparini, N.; Zhou, C.; Lin, Y.; Xue, D.-J.; Chen, B.; Johnston, A. K.; Wei, N.; Hedhili, M. N.; Wei, M.; Alsalloum, A. Y.; Maity, P.; Turedi, B.; Yang, C.; Baran, D.; Anthopoulos, T. D.; Han, Y.; Lu, Z.-H.; Mohammed, O. F.; Gao, F.; Sargent, E. H.; Bakr, O. M., Managing grains and interfaces via ligand anchoring enables $22.3 \%$-efficiency inverted perovskite solar cells. Nature Energy 2020, 5 (2), 131-140.

4. Aydin, E.; De Bastiani, M.; De Wolf, S., Defect and contact passivation for perovskite solar cells. Advanced Materials 2019, 31 (25), 1900428.

5. Zheng, X.; Troughton, J.; Gasparini, N.; Lin, Y.; Wei, M.; Hou, Y.; Liu, J.; Song, K.; Chen, Z.; Yang, C.; Turedi, B.; Alsalloum, A. Y.; Pan, J.; Chen, J.; Zhumekenov, A. A.; Anthopoulos, T. D.; Han, Y.; Baran, D.; Mohammed, O. F.; Sargent, E. H.; Bakr, O. M., Quantum Dots Supply Bulk-and Surface-Passivation Agents for Efficient and Stable Perovskite Solar Cells. Joule 2019, 3 (8), 1963-1976.

6. $\quad$ Stolterfoht, M.; Wolff, C. M.; Márquez, J. A.; Zhang, S.; Hages, C. J.; Rothhardt, D.; Albrecht, S.; Burn, P. L.; Meredith, P.; Unold, T.; Neher, D., Visualization and suppression of interfacial recombination for high-efficiency large-area pin perovskite solar cells. Nature Energy 2018, 3 (10), 847-854.

7. $\quad$ Akin, S.; Arora, N.; Zakeeruddin, S. M.; Graetzel, M.; Friend, R. H.; Dar, M. I., New Strategies for Defect Passivation in High-Efficiency Perovskite Solar Cells. Advanced Energy Materials 2020, 10 (13), 1903090.

8. Shi, D.; Adinolfi, V.; Comin, R.; Yuan, M.; Alarousu, E.; Buin, A.; Chen, Y.; Hoogland, S.; Rothenberger, A.; Katsiev, K.; Losovyj, Y.; Zhang, X.; Dowben, P. A.; Mohammed, O. F.; 
Sargent, E. H.; Bakr, O. M., Low trap-state density and long carrier diffusion in organolead trihalide perovskite single crystals. Science 2015, 347 (6221), 519-522.

9. Dong, Q.; Fang, Y.; Shao, Y.; Mulligan, P.; Qiu, J.; Cao, L.; Huang, J., Electron-hole diffusion lengths $>175 \mu \mathrm{m}$ in solution-grown $\mathrm{CH}_{3} \mathrm{NH}_{3} \mathrm{PbI}_{3}$ single crystals. Science 2015, 347 (6225), 967-970.

10. Wang, K.; Wu, C.; Hou, Y.; Yang, D.; Priya, S., Monocrystalline perovskite wafers/thin films for photovoltaic and transistor applications. Journal of Materials Chemistry A 2019, 7 (43), 24661-24690.

11. Chen, Z.; Dong, Q.; Liu, Y.; Bao, C.; Fang, Y.; Lin, Y.; Tang, S.; Wang, Q.; Xiao, X.; Bai, Y.; Deng, Y.; Huang, J., Thin single crystal perovskite solar cells to harvest below-bandgap light absorption. Nat. Commun. 2017, 8 (1), 1890.

12. Chen, Z.; Turedi, B.; Alsalloum, A.; Yang, C.; Zheng, X.; Gereige, I.; AlSaggaf, A.; Mohammed, O. F.; Bakr, O. M., Single-Crystal MAPbI3 Perovskite Solar Cells Exceeding 21\% Power Conversion Efficiency. ACS Energy Letters 2019, 4 (6), 1258-1259.

13. Alsalloum, A. Y.; Turedi, B.; Zheng, X.; Mitra, S.; Zhumekenov, A. A.; Lee, K.; Maity, P.; Gereige, I.; Alsaggaf, A.; Roqan, I. S.; Mohammed, O. F.; Bakr, O. M., Low Temperature Crystallization Enables 21.9\% Efficient Single-Crystal MAPbI3 Inverted Perovskite Solar Cells. ACS Energy Letters 2020, 5 (2), 657-662.

14. Ma, C.; Park, N.-G., A Realistic Methodology for 30\% Efficient Perovskite Solar Cells. Chem 2020, 6 (6), 1254-1264.

15. Zheng, X.; Alsalloum, A. Y.; Hou, Y.; Sargent, E. H.; Bakr, O. M., All-Perovskite Tandem Solar Cells: A Roadmap to Uniting High Efficiency with High Stability. Accounts of Materials Research 2020, 1 (1), 63-76.

16. Nayak, P. K.; Moore, D. T.; Wenger, B.; Nayak, S.; Haghighirad, A. A.; Fineberg, A.; Noel, N. K.; Reid, O. G.; Rumbles, G.; Kukura, P.; Vincent, K. A.; Snaith, H. J., Mechanism for rapid growth of organic-inorganic halide perovskite crystals. Nature Communications 2016, 7 (1), 13303.

17. Yang, Y.; Yang, M.; Moore, David T.; Yan, Y.; Miller, Elisa M.; Zhu, K.; Beard, Matthew C., Top and bottom surfaces limit carrier lifetime in lead iodide perovskite films. Nature Energy 2017, 2 (2), 16207.

18. Ni, Z.; Bao, C.; Liu, Y.; Jiang, Q.; Wu, W.-Q.; Chen, S.; Dai, X.; Chen, B.; Hartweg, B.; Yu, Z.; Holman, Z.; Huang, J., Resolving spatial and energetic distributions of trap states in metal halide perovskite solar cells. Science 2020, 367 (6484), 1352-1358.

19. Wolff, C. M.; Caprioglio, P.; Stolterfoht, M.; Neher, D., Nonradiative Recombination in Perovskite Solar Cells: The Role of Interfaces. Advanced Materials 2019, 31, 1902762.

20. Wetzelaer, G. J. A.; Scheepers, M.; Sempere, A. M.; Momblona, C.; Ávila, J.; Bolink, H. J., Trap-assisted non-radiative recombination in organic-inorganic perovskite solar cells. Advanced Materials 2015, 27 (11), 1837-1841.

21. Stranks, S. D., Nonradiative losses in metal halide perovskites. ACS Energy Letters 2017, 2 (7), 1515-1525.

22. NREL Best Research-Cell Efficiencies. 2021, https://www.nrel.gov/pv/cellefficiency.html.

23. Polman, A.; Knight, M.; Garnett, E. C.; Ehrler, B.; Sinke, W. C., Photovoltaic materials: Present efficiencies and future challenges. Science 2016, 352 (6283), aad4424.

24. Kurtz, S. R.; McConnell, R. In Requirements for a 20\%-efficient polycrystalline GaAs solar cell, AIP Conference Proceedings, American Institute of Physics: 1997; pp 191-205. 
25. Queisser, H. J.; Haller, E. E., Defects in Semiconductors: Some Fatal, Some Vital. Science 1998, 281 (5379), 945-950.

26. Ono, L. K.; Liu, S. F.; Qi, Y., Reducing Detrimental Defects for High-Performance Metal Halide Perovskite Solar Cells. Angewandte Chemie (International Ed. in English) 2020, 59 (17), 6676.

27. Green, M. A.; Dunlop, E. D.; Hohl-Ebinger, J.; Yoshita, M.; Kopidakis, N.; Ho-Baillie, A. W., Solar cell efficiency tables (version 55). Progress in Photovoltaics: Research and Applications 2019, 28, 3-15.

28. Schnitzer, I.; Yablonovitch, E.; Caneau, C.; Gmitter, T., Ultrahigh spontaneous emission quantum efficiency, 99.7\% internally and 72\% externally, from AlGaAs/GaAs/AlGaAs double heterostructures. Applied physics letters 1993, 62 (2), 131-133.

29. Schindler, F.; Fell, A.; Müller, R.; Benick, J.; Richter, A.; Feldmann, F.; Krenckel, P.; Riepe, S.; Schubert, M. C.; Glunz, S. W., Towards the efficiency limits of multicrystalline silicon solar cells. Solar Energy Materials and Solar Cells 2018, 185, 198-204.

30. Yoshikawa, K.; Kawasaki, H.; Yoshida, W.; Irie, T.; Konishi, K.; Nakano, K.; Uto, T.; Adachi, D.; Kanematsu, M.; Uzu, H.; Yamamoto, K., Silicon heterojunction solar cell with interdigitated back contacts for a photoconversion efficiency over 26\%. Nature Energy 2017, 2 (5), 17032.

31. Yan, Y.; Yin, W.-J.; Wu, Y.; Shi, T.; Paudel, N. R.; Li, C.; Poplawsky, J.; Wang, Z.; Moseley, J.; Guthrey, H.; Moutinho, H.; Pennycook, S. J.; Al-Jassim, M. M., Physics of grain boundaries in polycrystalline photovoltaic semiconductors. Journal of Applied Physics 2015, 117 (11), 112807.

32. Becker, J. J.; Boccard, M.; Campbell, C. M.; Zhao, Y.; Lassise, M.; Holman, Z. C.; Zhang, Y.-H., Loss analysis of monocrystalline CdTe solar cells with $20 \%$ active-area efficiency. IEEE journal of photovoltaics 2017, 7 (3), 900-905.

33. Ball, J. M.; Petrozza, A., Defects in perovskite-halides and their effects in solar cells. Nature Energy 2016, 1 (11), 1-13.

34. Shan, W.; Saidi, W. A., Segregation of native defects to the grain boundaries in methylammonium lead iodide perovskite. The journal of physical chemistry letters 2017, 8 (23), 5935-5942.

35. Long, R.; Liu, J.; Prezhdo, O. V., Unravelling the effects of grain boundary and chemical doping on electron-hole recombination in $\mathrm{CH} 3 \mathrm{NH} 3 \mathrm{PbI} 3$ perovskite by time-domain atomistic simulation. Journal of the American Chemical Society 2016, 138 (11), 3884-3890.

36. de Quilettes, D. W.; Vorpahl, S. M.; Stranks, S. D.; Nagaoka, H.; Eperon, G. E.; Ziffer, M. E.; Snaith, H. J.; Ginger, D. S., Impact of microstructure on local carrier lifetime in perovskite solar cells. Science 2015, 348 (6235), 683-686.

37. Jankowska, J.; Long, R.; Prezhdo, O. V., Quantum dynamics of photogenerated charge carriers in hybrid perovskites: Dopants, grain boundaries, electric order, and other realistic aspects. ACS Energy Letters 2017, 2 (7), 1588-1597.

38. Dong, Q.; Song, J.; Fang, Y.; Shao, Y.; Ducharme, S.; Huang, J., Lateral-structure singlecrystal hybrid perovskite solar cells via piezoelectric poling. Advanced Materials 2016, 28 (14), 2816-2821.

39. Schlipf, J.; Askar, A. M.; Pantle, F.; Wiltshire, B. D.; Sura, A.; Schneider, P.; Huber, L.; Shankar, K.; Müller-Buschbaum, P., Top-down approaches towards single crystal perovskite solar cells. Scientific reports 2018, 8 (1), 1-8. 
40. Saidaminov, M. I.; Abdelhady, A. L.; Murali, B.; Alarousu, E.; Burlakov, V. M.; Peng, W.; Dursun, I.; Wang, L.; He, Y.; Maculan, G.; Goriely, A.; Wu, T.; Mohammed, O. F.; Bakr, O. M., High-quality bulk hybrid perovskite single crystals within minutes by inverse temperature crystallization. Nature communications 2015, 6, 7586.

41. Liu, Y.; Yang, Z.; Liu, S., Recent Progress in Single-Crystalline Perovskite Research Including Crystal Preparation, Property Evaluation, and Applications. Advanced Science 2018, 5 (1), 1700471.

42. He, Y.; Petryk, M.; Liu, Z.; Chica, D. G.; Hadar, I.; Leak, C.; Ke, W.; Spanopoulos, I.; Lin, W.; Chung, D. Y.; Wessels, B. W.; He, Z.; Kanatzidis, M. G., CsPbBr3 perovskite detectors with $1.4 \%$ energy resolution for high-energy $\gamma$-rays. Nature Photonics 2020, 15, 36-42.

43. Li, X.; He, Y.; Kepenekian, M.; Guo, P.; Ke, W.; Even, J.; Katan, C.; Stoumpos, C. C.; Schaller, R. D.; Kanatzidis, M. G., Three-dimensional Lead Iodide Perovskitoid Hybrids with High X-ray Photoresponse. Journal of the American Chemical Society 2020, 142 (14), 66256637.

44. Haughn, C.; Schmieder, K.; Zide, J.; Barnett, A.; Ebert, C.; Opila, R.; Doty, M., Quantification of trap state densities in GaAs heterostructures grown at varying rates using intensity-dependent time resolved photoluminescence. Applied Physics Letters 2013, 102 (18), 182108.

45. Tan, J.; Cuevas, A.; MacDonald, D.; Trupke, T.; Bardos, R.; Roth, K., On the electronic improvement of multi-crystalline silicon via gettering and hydrogenation. Progress in

Photovoltaics: Research and Applications 2008, 16 (2), 129-134.

46. Macdonald, D.; Cuevas, A., Trapping of minority carriers in multicrystalline silicon. Applied Physics Letters 1999, 74 (12), 1710-1712.

47. Balcioglu, A.; Ahrenkiel, R.; Hasoon, F., Deep-level impurities in CdTe/CdS thin-film solar cells. Journal of Applied Physics 2000, 88 (12), 7175-7178.

48. Kerr, L.; Li, S. S.; Johnston, S.; Anderson, T.; Crisalle, O.; Kim, W.; Abushama, J.; Noufi, R., Investigation of defect properties in $\mathrm{Cu}$ (In, Ga) Se2 solar cells by deep-level transient spectroscopy. Solid-State Electronics 2004, 48 (9), 1579-1586.

49. Haynes, J.; Hornbeck, J., Trapping of minority carriers in silicon. II. n-type silicon. Physical Review 1955, 100 (2), 606.

50. Liu, Y.; Zhang, Y.; Yang, Z.; Yang, D.; Ren, X.; Pang, L.; Liu, S., Thinness-and shapecontrolled growth for ultrathin single-crystalline perovskite wafers for mass production of superior photoelectronic devices. Advanced Materials 2016, 28 (41), 9204-9209.

51. Peng, W.; Wang, L.; Murali, B.; Ho, K. T.; Bera, A.; Cho, N.; Kang, C. F.; Burlakov, V. M.; Pan, J.; Sinatra, L.; Ma, C.; Xu, W.; Shi, D.; Alarousu, E.; Goriely, A.; He, J. H.;

Mohammed, O. F.; Wu, T.; Bakr, O. M., Solution-Grown Monocrystalline Hybrid Perovskite Films for Hole-Transporter-Free Solar Cells. Adv Mater 2016, 28 (17), 3383-90.

52. Zhumekenov, A. A.; Burlakov, V. M.; Saidaminov, M. I.; Alofi, A.; Haque, M. A.; Turedi, B.; Davaasuren, B.; Dursun, I.; Cho, N.; El-Zohry, A. M.; De Bastiani, M.; Giugni, A.; Torre, B.; Di Fabrizio, E.; Mohammed, O. F.; Rothenberger, A.; Wu, T.; Goriely, A.; Bakr, O. M., The role of surface tension in the crystallization of metal halide perovskites. ACS Energy Letters 2017, 2 (8), 1782-1788.

53. Cho, N.; Li, F.; Turedi, B.; Sinatra, L.; Sarmah, S. P.; Parida, M. R.; Saidaminov, M. I.; Murali, B.; Burlakov, V. M.; Goriely, A.; Mohammed, O. F.; Wu, T.; Bakr, O. M., Pure crystal orientation and anisotropic charge transport in large-area hybrid perovskite films. Nature communications 2016, 7 (1), 1-11. 
54. Lee, L.; Baek, J.; Park, K. S.; Lee, Y.-E.; Shrestha, N. K.; Sung, M. M., Wafer-scale single-crystal perovskite patterned thin films based on geometrically-confined lateral crystal growth. Nature communications 2017, 8 (1), 1-8.

55. Rao, H.-S.; Chen, B.-X.; Wang, X.-D.; Kuang, D.-B.; Su, C.-Y., A micron-scale laminar $\mathrm{MAPbBr} 3$ single crystal for an efficient and stable perovskite solar cell. Chemical Communications 2017, 53 (37), 5163-5166.

56. Juarez-Perez, E. J.; Ono, L. K.; Maeda, M.; Jiang, Y.; Hawash, Z.; Qi, Y., Photodecomposition and thermal decomposition in methylammonium halide lead perovskites and inferred design principles to increase photovoltaic device stability. Journal of Materials Chemistry A 2018, 6 (20), 9604-9612.

57. Snaith, H. J.; Abate, A.; Ball, J. M.; Eperon, G. E.; Leijtens, T.; Noel, N. K.; Stranks, S. D.; Wang, J. T.-W.; Wojciechowski, K.; Zhang, W., Anomalous hysteresis in perovskite solar cells. The journal of physical chemistry letters 2014, 5 (9), 1511-1515.

58. Chen, B.; Yang, M.; Priya, S.; Zhu, K., Origin of J-V hysteresis in perovskite solar cells. The journal of physical chemistry letters 2016, 7 (5), 905-917.

59. Haruyama, J.; Sodeyama, K.; Han, L.; Tateyama, Y., First-principles study of ion diffusion in perovskite solar cell sensitizers. Journal of the American Chemical Society 2015, 137 (32), 10048-10051.

60. Ma, D.; Mai, L.; Saliba, M.; Sargent, E. H.; Kamat, P. V., Energy Selects: Perovskite Photovoltaics and Storage Batteries. ACS Energy Letters 2019, 4 (6), 1455-1457.

61. Wu, B.; Nguyen, H. T.; Ku, Z.; Han, G.; Giovanni, D.; Mathews, N.; Fan, H. J.; Sum, T. C., Discerning the surface and bulk recombination kinetics of organic-inorganic halide perovskite single crystals. Advanced Energy Materials 2016, 6 (14), 1600551.

62. Grancini, G.; D'Innocenzo, V.; Dohner, E. R.; Martino, N.; Kandada, A. S.; Mosconi, E.; De Angelis, F.; Karunadasa, H. I.; Hoke, E. T.; Petrozza, A., CH 3 NH 3 PbI 3 perovskite single crystals: surface photophysics and their interaction with the environment. Chemical science 2015, 6 (12), 7305-7310.

63. Fang, H.-H.; Adjokatse, S.; Wei, H.; Yang, J.; Blake, G. R.; Huang, J.; Even, J.; Loi, M. A., Ultrahigh sensitivity of methylammonium lead tribromide perovskite single crystals to environmental gases. Science Advances 2016, 2 (7), e1600534.

64. Burgelman, M.; Nollet, P.; Degrave, S., Modelling polycrystalline semiconductor solar cells. Thin solid films 2000, 361, 527-532.

65. Yadav, P.; Pandey, K.; Bhatt, P.; Raval, D.; Tripathi, B.; Pandey, M. K.; Kumar, M., Exploring the performance limiting parameters of perovskite solar cell through experimental analysis and device simulation. Solar Energy 2015, 122, 773-782.

66. Minemoto, T.; Murata, M., Device modeling of perovskite solar cells based on structural similarity with thin film inorganic semiconductor solar cells. Journal of applied physics 2014, $116(5), 054505$.

67. De Wolf, S.; Holovsky, J.; Moon, S.-J.; Löper, P.; Niesen, B.; Ledinsky, M.; Haug, F.-J.; Yum, J.-H.; Ballif, C., Organometallic halide perovskites: sharp optical absorption edge and its relation to photovoltaic performance. The journal of physical chemistry letters 2014, 5 (6), 1035 1039.

68. Adinolfi, V.; Yuan, M.; Comin, R.; Thibau, E. S.; Shi, D.; Saidaminov, M. I.; Kanjanaboos, P.; Kopilovic, D.; Hoogland, S.; Lu, Z. H.; Bakr, O. M.; Sargent, E. H., The InGap Electronic State Spectrum of Methylammonium Lead Iodide Single-Crystal Perovskites. Advanced materials 2016, 28 (17), 3406-3410. 
69. Jiang, Q.; Zhao, Y.; Zhang, X.; Yang, X.; Chen, Y.; Chu, Z.; Ye, Q.; Li, X.; Yin, Z.; You, J., Surface passivation of perovskite film for efficient solar cells. Nature Photonics 2019, 13 (7), 460-466.

70. Tan, H.; Jain, A.; Voznyy, O.; Lan, X.; De Arquer, F. P. G.; Fan, J. Z.; QuinteroBermudez, R.; Yuan, M.; Zhang, B.; Zhao, Y.; Fan, F.; Li, P.; Quan, L. N.; Zhao, Y.; Lu, Z.-H.; Yang, Z.; Hoogland, S.; Sargent, E. H., Efficient and stable solution-processed planar perovskite solar cells via contact passivation. Science 2017, 355 (6326), 722-726.

71. Zheng, X.; Chen, B.; Dai, J.; Fang, Y.; Bai, Y.; Lin, Y.; Wei, H.; Zeng, Xiao C.; Huang, J., Defect passivation in hybrid perovskite solar cells using quaternary ammonium halide anions and cations. Nature Energy 2017, 2 (7), 17102.

72. Abdi-Jalebi, M.; Andaji-Garmaroudi, Z.; Cacovich, S.; Stavrakas, C.; Philippe, B.;

Richter, J. M.; Alsari, M.; Booker, E. P.; Hutter, E. M.; Pearson, A. J.; Lilliu, S.; Savenije, T. J.; Rensmo, H.; Divitini, G.; Ducati, C.; Friend, R. H.; Stranks, S. D., Maximizing and stabilizing luminescence from halide perovskites with potassium passivation. Nature 2018, 555 (7697), 497501.

73. Yin, W.-J.; Shi, T.; Yan, Y., Unusual defect physics in CH3NH3PbI3 perovskite solar cell absorber. Applied Physics Letters 2014, 104 (6), 063903.

74. Zheng, X.; Yuan, S.; Liu, J.; Yin, J.; Yuan, F.; Shen, W.-S.; Yao, K.; Wei, M.; Zhou, C.; Song, K.; Zhang, B.-B.; Lin, Y.; Hedhili, M. N.; Wehbe, N.; Han, Y.; Sun, H.-T.; Lu, Z.-H.; Anthopoulos, T. D.; Mohammed, O. F.; Sargent, E. H.; Liao, L.-S.; Bakr, O. M., Chlorine Vacancy Passivation in Mixed Halide Perovskite Quantum Dots by Organic Pseudohalides Enables Efficient Rec. 2020 Blue Light-Emitting Diodes. ACS Energy Letters 2020, 5 (3), 793 798.

75. Xue, J.; Wang, R.; Yang, Y., The surface of halide perovskites from nano to bulk. Nature Reviews Materials 2020, 5, 809-827.

76. Song, Y.; Bi, W.; Wang, A.; Liu, X.; Kang, Y.; Dong, Q., Efficient lateral-structure perovskite single crystal solar cells with high operational stability. Nature Communications 2020, $11(1), 1-8$.

77. Wang, L.; Zhou, H.; Hu, J.; Huang, B.; Sun, M.; Dong, B.; Zheng, G.; Huang, Y.; Chen, Y.; Li, L.; Xu, Z.; Li, N.; Liu, Z.; Chen, Q.; Sun, L.-D.; Yan, C.-H., A Eu ${ }^{3+}-\mathrm{Eu}^{2+}$ ion redox shuttle imparts operational durability to Pb-I perovskite solar cells. Science 2019, 363 (6424), 265-270.

78. Shi, L.; Bucknall, M. P.; Young, T. L.; Zhang, M.; Hu, L.; Bing, J.; Lee, D. S.; Kim, J.; Wu, T.; Takamure, N.; McKenzie, D. R.; Huang, S.; Green, M. A.; Ho-Baillie, A. W. Y., Gas chromatography-mass spectrometry analyses of encapsulated stable perovskite solar cells.

Science 2020, 368 (6497), eaba2412.

79. Feng, Y.; Pan, L.; Wei, H.; Liu, Y.; Ni, Z.; Zhao, J.; Rudd, P. N.; Cao, L. R.; Huang, J., Low defects density $\mathrm{CsPbBr} 3$ single crystals grown by an additive assisted method for gammaray detection. Journal of Materials Chemistry C 2020, 8 (33), 11360-11368.

80. Jao, M.-H.; Lu, C.-F.; Tai, P.-Y.; Su, W.-F., Precise Facet Engineering of Perovskite Single Crystals by Ligand-Mediated Strategy. Crystal Growth \& Design 2017, 17 (11), 59455952.

81. Kim, D.; Yun, J.-H.; Lyu, M.; Kim, J.; Lim, S.; Yun, J. S.; Wang, L.; Seidel, J., Probing Facet-Dependent Surface Defects in MAPbI3 Perovskite Single Crystals. The Journal of Physical Chemistry C 2019, 123 (23), 14144-14151. 
82. Wang, R.; Xue, J.; Wang, K.-L.; Wang, Z.-K.; Luo, Y.; Fenning, D.; Xu, G.; Nuryyeva, S.; Huang, T.; Zhao, Y.; Yang, J. L.; Zhu, J.; Wang, M.; Tan, S.; Yavuz, I.; Houk, K. N.; Yang, Y., Constructive molecular configurations for surface-defect passivation of perovskite photovoltaics. Science 2019, 366 (6472), 1509-1513.

83. Lei, Y.; Chen, Y.; Zhang, R.; Li, Y.; Yan, Q.; Lee, S.; Yu, Y.; Tsai, H.; Choi, W.; Wang, K.; Luo, Y.; Gu, Y.; Zheng, X.; Wang, C.; Wang, C.; Hu, H.; Li, Y.; Qi, B.; Lin, M.; Zhang, Z.; Dayeh, S. A.; Pharr, M.; Fenning, D. P.; Lo, Y.-H.; Luo, J.; Yang, K.; Yoo, J.; Nie, W.; Xu, S., A fabrication process for flexible single-crystal perovskite devices. Nature 2020, 583 (7818), 790795.

84. Yang, S.; Chen, S.; Mosconi, E.; Fang, Y.; Xiao, X.; Wang, C.; Zhou, Y.; Yu, Z.; Zhao, J.; Gao, Y.; Angelis, F. D.; Huang, J., Stabilizing halide perovskite surfaces for solar cell operation with wide-bandgap lead oxysalts. Science 2019, 365 (6452), 473-478.

85. Li, F.; Deng, X.; Qi, F.; Li, Z.; Liu, D.; Shen, D.; Qin, M.; Wu, S.; Lin, F.; Jang, S.-H.; Zhang, J.; Lu, X.; Lei, D.; Lee, C.-S.; Zhu, Z.; Jen, A. K.-Y., Regulating Surface Termination for Efficient Inverted Perovskite Solar Cells with Greater Than 23\% Efficiency. Journal of the American Chemical Society 2020, 142 (47), 20134-20142.

86. Luan, M.; Song, J.; Wei, X.; Chen, F.; Liu, J., Controllable growth of bulk cubic-phase $\mathrm{CH} 3 \mathrm{NH} 3 \mathrm{PbI} 3$ single crystal with exciting room-temperature stability. CrystEngComm 2016, 18 (28), 5257-5261.

87. Moloney, E. G.; Yeddu, V.; Saidaminov, M. I., Strain Engineering in Halide Perovskites. ACS Materials Letters 2020, 2 (11), 1495-1508.

88. Saliba, M.; Matsui, T.; Seo, J.-Y.; Domanski, K.; Correa-Baena, J.-P.; Nazeeruddin, M. K.; Zakeeruddin, S. M.; Tress, W.; Abate, A.; Hagfeldt, A.; Grätzel, M., Cesium-containing triple cation perovskite solar cells: improved stability, reproducibility and high efficiency. Energy \& environmental science 2016, 9 (6), 1989-1997.

89. Saliba, M., Polyelemental, multicomponent perovskite semiconductor libraries through combinatorial screening. Advanced Energy Materials 2019, 9 (25), 1803754.

90. Wang, Y.; Dar, M. I.; Ono, L. K.; Zhang, T.; Kan, M.; Li, Y.; Zhang, L.; Wang, X.; Yang, Y.; Gao, X.; Qi, Y.; Grätzel, M.; Zhao, Y., Thermodynamically stabilized $\beta$-CsPbI3-based perovskite solar cells with efficiencies> 18\%. Science 2019, 365 (6453), 591-595.

91. Liu, Y.; Ren, X.; Zhang, J.; Yang, Z.; Yang, D.; Yu, F.; Sun, J.; Zhao, C.; Yao, Z.; Wang, B.; Wei, Q.; Xiao, F.; Fan, H.; Deng, H.; Deng, L.; Liu, S. F., 120 mm single-crystalline perovskite and wafers: towards viable applications. Science China Chemistry 2017, 60 (10), 1367-1376.

92. Chen, J.; Morrow, D. J.; Fu, Y.; Zheng, W.; Zhao, Y.; Dang, L.; Stolt, M. J.; Kohler, D. D.; Wang, X.; Czech, K. J.; Hautzinger, M. P.; Shen, S.; Guo, L.; Pan, A.; Wright, J. C.; Jin, S., Single-crystal thin films of cesium lead bromide perovskite epitaxially grown on metal oxide perovskite (SrTiO3). Journal of the American Chemical Society 2017, 139 (38), 13525-13532. 93. Chen, J.; Fu, Y.; Samad, L.; Dang, L.; Zhao, Y.; Shen, S.; Guo, L.; Jin, S., Vapor-phase epitaxial growth of aligned nanowire networks of cesium lead halide perovskites $(\mathrm{CsPbX} 3, \mathrm{X}=$ Cl, Br, I). Nano letters 2017, 17 (1), 460-466. 